\title{
Skin covered myelomeningoceles do not exist: What are these lesions? \\ Hector James*
}

\author{
Address: Lucy B. Gooding Pediatric Neurosurgery Center, University of Florida and Wolfson Children's Hospital, Jacksonville, Florida, USA \\ Email: Hector James* - hejames@ufl.edu \\ * Corresponding author
}

from 49th Annual Meeting of the Society for Research into Hydrocephalus and Spina Bifida

Barcelona, Spain, 29 June - 2 July 2005

Published: 30 December 2005

Cerebrospinal Fluid Research 2005, 2(SuppI I):S20 doi:I0.II86/I743-8454-2-SI-S20

\section{Background}

The author reports a clinical experience of congenital midline skin covered lesions and discusses the diagnostic approach, neuro imaging, operative management, and follow-up, with particular emphasis on patients with terminal myelocystocele.

\section{Materials and methods}

During the period of August 1977 through December 2004, the author evaluated children with skin covered spinal lesions, and made the diagnosis of: meningocele (6), lipomas and lipomeningoceles (42), hamartomas (9), teratomas (6), and terminal myelocystocele (8).

\section{Neuro Imaging}

The patients were initially diagnosed by either spinal high resolution ultrasonography, spinal computed tomography (CT), or spinal magnetic resonance imaging (MRI). All the patients with terminal myelocystocele underwent preoperative and postoperative spinal MRI.

\section{Operative Findings}

All patients underwent operative confirmation of the clinical diagnosis at the time of corrective surgery for the underlying disease. The patients with terminal myelocystocele underwent release of the tethered cord, radical but subtotal resection of the lipoma, and myelotomy and drainage of the syringocele with microlaser neurosurgery.

\section{Results}

Of the 8 patients with terminal myelocystocele, 4 had associated abdominal wall defects (i.e., bladder exstrophy) and 4 did not. Patients without abdominal wall defects were diagnosed earlier in life and underwent oper- ative intervention sooner than those with abdominal defects. The former had better neurological outcome and less operative interventions. These findings will be presented.

\section{Conclusion}

There is a wide variety of congenital midline skin covered lesions in the dorsal medial embryo. Correct diagnosis enables an earlier and more effective management. Terminal myelocystoceles are a distinct clinical entity that is at risk of having a late diagnosis and consequently a delay in treatment.

\section{Acknowledgements}

This report has been supported in part by the Foundation for Pediatric and Laser Neurosurgery, Inc. and the Lucy B. Gooding Charitable Foundation Trust. 